\title{
DRUG USE EVALUATION OF CORTICOSTEROIDSIN SYSTEMIC LUPUS ERYTHEMATOSUS OUTPATIENTS
}

\author{
M.Caecilia N.Setiawati ${ }^{1}$, Kertia Nyoman ${ }^{2}$ \\ ${ }^{1}$ Sekolah Tinggi Ilmu Farmasi Yayasan Farmasi Semarang \\ Letjend Sarwo Edi Wibowo Km 1, Plamongansari Semarang 50193 \\ ${ }^{2}$ Faculty of Medicine, Gadjah Mada University, Yogyakarta \\ Farmako Sekip Utara, Yogyakarta, 55281 \\ Corresponding author : caecil_nanny@yahoo.co.id
}

\begin{abstract}
Corticosteroids was the mainstay therapy for SLE, an autoimmune chronic desease. Prolonged use of Corticosteroid caused many side effects' risk. This study was aimed to evaluate corticosteroid drug use in SLE outpatients. This study was conducted on April 2017 to August 2017. Cross sectional design was used and presented with analytical descriptive. The result is, 192 SLE outpatients pass the inclusion criteria and $98,96 \%$ are women. Methylprednisolon per oral is the most corticosteroid used for SLE outpatients, combine with 1 other immnunsuppresant ( 65,10 \%) and combine with 2 other immunsuppresant ( $8,33 \%)$. From BMI, 26,05\% subjects are overweight, perhaps because of corticosteroids side effect, such as weight gain. More than a half SLE outpatients $(58,33 \%)$ get Calcium supplement and vitamin D3 as prophylactive for osteoporosis because of prolonged use of corticosteroid and 61 SLE outpatients get drug for gastrointestinal use to avoid peptic ulcer. There are 44 cases of potential corticosteroid interaction with other drug that are given together, the most are corticosteroid and aspirin interaction, on 14 patients.
\end{abstract}

Keywords:corticosteroid, Systemic Lupus Erythematosus,outpatients, drug use evaluation

\section{Introduction}

Systemic Lupus Erythematosus (SLE) is a chronic multisystem autoimmune disorder characterized by the development of autoantibodies and immune complexes in various clinical manifestations and tissues damage (Tsang-A-Sjoe and Bultink, 2015). According to Indonesian Lupus Foundation (Yayasan Lupus Indonesia) in the last decade, the SLE patients increases every years. Therefore, proper medication is needed so that the risk of SLE are not fatal and an evaluation of the drugs use in SLE patients is necessary. Morbidity and mortality of SLE patients is still quite high. As many as $40 \%$ of SLE deaths occur 12-25 years after being diagnosed, mostly due to infections and complications of chronic steroids and immunsuppresant therapy (Rahman dan Isenberg, 2008).

Corticosteroids and imunsuppresant are the mainstay therapy in SLE cases. Volume 1 Issue 1 (2018)
Problems with long-term steroid use such as osteoporosis, the risk of infection, worsen hypertension, provoke diabetes and have an adverse effect on lipid profile which may contribute to increase death from heart disease and the risk of gastrointestinal bleeding (Moroni and Ponticelli,2017).

Evaluation of corticosteroid use in SLE patients aims to improve the patient's knowledge in carrying out corticosteroid therapy, so that an optimal therapeutic outcome will be obtained. Evaluation of drug use in SLE patients has been done (Setiawati, 2013), but not focused on corticosteroids and the number of subjects of that study was very limited, only 18 patients. This study evaluated the use of corticosteroids in outpatient SLE patients, with a total of 192 subjects.

\section{Methods}

This corticosteroids drug use on Systemic Lupus Erythematosus(SLE)outpatients, is 
a non experimental research, observational analytical, cross sectional, for SLE outpatients from many hospitals in Indonesia, in AprilAgustus 2017 and patients fulfill the entry criterias

The study was approved by the Research Ethic Committee in Public health Faculty Diponegoro University Semarang

The inclussion criteria: patients diagnosedSLE for more than 3 months, got corticosteroids therapy and agree to be the subject of this research.

The Data were analyzed by producing descriptive statistics using statistical product and service solution (SPSS) version 16 ..

\section{Results And Discussion}

\section{Characteristics of the subjects}

Of 222 SLE patients who agree to be the subjects of this research, only 192 (86,49\%) who met the entry criteria : being diagnosed more than 3 month and got corticosteroids (table 1). Many SLE patients got corticosteroids therapy, showed that corticosteroids are the mainstay therapy for SLE (Kasturi and Sammaritano, 2016)

Estrogen influence in SLE pathogenetics. Estrogen increased autoimmunity with producing more autoantibody, inhibit Natural Killer cell function, and caused athropy on thymus gland (Wallace, 2007: 173). According to age, most patients are on 30-40 years, which is in productive age where estrogen are still producted. The amount of SLE patients reduced on elderly women who has menopaused (YLI, 2011).

More than a half of the subjects, are normal $(57,81 \%)$ according to BMI from WHO, 16,67\% are overweight (pre obess) and $9,38 \%$ subjects are obess. Corticosteroid side effects are weight gain (Wung et al., 2008). On table I, we can see that $93,75 \%$ patients has been diagnosed more than 1 year, 28 subjects $(14,58 \%)$ diagnosed more than 10 years. This showed that SLE is a chronical ill (Gordon and Isenberg, 2016).

2. Corticosteroids usage pattern

Although the use of corticosteroids can cause a number of deaths but its use can not only eliminate symptoms, but also reduce mortality in SLE, so that SLE survival increases (Chatham and Kimberly, 2001). The most used corticosteroid is methylprednisolone, given to 186 patients (96.87\%), the remaining 5 patients received prednisone $(2.60 \%)$ and dexamethasone was given only in 1 patient $(0.52 \%)$. The prescribed dose of methylprednisolone varies, from $4 \mathrm{mg}$ every other day, to $16 \mathrm{mg}$ twice a day. Corticosteroid dose accuracy cannot be evaluated in this study, because corticosteroid dosing is based on the activity of SLE disease, whereas in this study, there was no measurement of SLE disease activity.

The research of Bitencourt Dias et al, 2011 states that there is no difference between Single corticosteroids and two immunosuppressants in inducing remission in patients with SLE nephritis (Bitencourt Dias et al., 2011). In this study, corticosteroids were given singly in $26.56 \%$ of SLE patients and used in combination with other immunosuppressants, as listed in Table II. The most widely used immunosuppresant is mycophenolat mofetil in 54 patients $(28.12 \%)$, antimalarial hydroxychloroquin in 32 patients (16.67\%), azathioprine in 27 patients $(14.06 \%)$, cyclosporine in 16 patients $(8.33 \%)$, methotrexate in 7 patients $(3.65 \%)$ and sulfazalasin were given in 2 patients (1.04\%). The use of corticosteroids along with other antimalarials and imunsuppressants can reduce the dose of corticosteroids, so that side effects that may occur can be reduced (Ruiz-Irastorza et al., 2012).

The use of a single corticosteroid or combination with other immunosuppressants can induce remission in one type of lupus nephritis, podocytopopathic lupus, but recurrence is more common in single therapy than in combination therapy (Hu et al., 2015) 
Table 1. Qualitative demographic variables of respondents $(\mathrm{n}=192)$

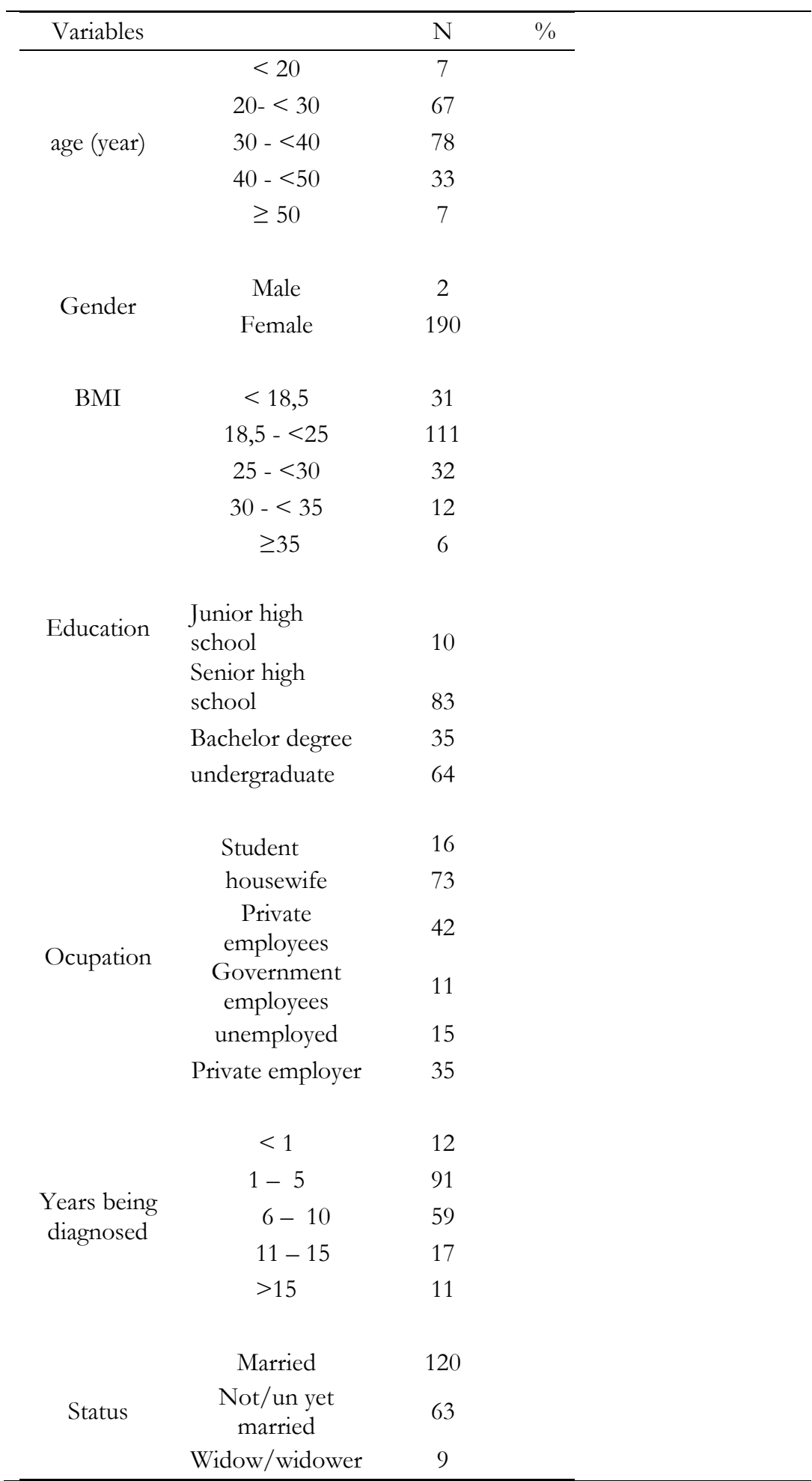


Table 2. Corticosteroid ussage pattern

\begin{tabular}{crr}
\hline corticosteroid (CS) & \multicolumn{1}{c}{$\mathbf{N}$} & \multicolumn{1}{c}{$\%$} \\
\hline Singly & 51 & 26,56 \\
CS + 1 immunsuppresant & 125 & 65,10 \\
CS + 2 immunsuppresant & 16 & 8,33
\end{tabular}

3. Other drugs

There are many drugs prescribed for SLE outpatients to counter the adverse effect due to corticosteroids used, which will increase according to dosage and duration administration. The most side effects are musculoskeletal complication such as osteoporosis and myopathy (Ruiz-Irastorza et al., 2012). The other side effect were endocrine manifestation, such as hyperglycemia and weight gain, which is reversible on the tappering but can cause diabetes, obesity, hypertension, hyperlipid and atherosclerosis. Cardiovascular complication, such as myocardial infarction and cardiovascular disease often occured in SLE. The other side effects are infection, pschycological disturbance, peptic ulcer, catharact and glaucoma (Moroni and Ponticelli, 2017)

In this study, only 4 patients $(2,08 \%)$ received antibiotic, none of whom received antiviral or antiparasitic drugs so that it could be stated that the infection side effect because of corticosteroids used in the study subject were only a few. Different with the study ofYoussef et al., 2016, which stated that serious and opportunities infections can occur in long term corticosteroids useand depend on the dosage. The incidence of osteoporosis due to long term use of corticosteroidsalthough in low doses is the risk of the most common side effect(RuizIrastorza et al., 2012).

Doctors gave Calcium and Vitamin D3 supplements to 112 subject $(58,33 \%)$ to prevent osteoporosis. The other drugs, also possible to overcome the side effect of corticosteroids, 61 patients $(31,77 \%)$ get the gastrointestinal drugs (most are proton pump inhibitor) to prevent peptic ulcer, 36 patients $(18,75 \%)$ get antihypertension drugs ( most are Angiotensin Receptor Blocker) cause Corticosteroids can cause sodium retention and increase the blood pressure. Twenty patients $(10,42 \%)$ get blood thinner (most is aspirin) to prevent atherosclerosis, 13 patients (6,77\%)get antihyperlipid ( the most statin group), 9 patients $(4,69 \%)$ got neurotropic vitamin, to prevent myopati and 4 patients $(2,08 \%)$ received oral hypoglycemic (metformin and glymepirid). The other corticosteroids side effects is mental disorder, but in this study, only 4 patients $(2,08 \%)$ get antidrepessive drugs.

\section{Drug Interaction}

There is some potential interactions on corticosteroid use. Methylprednisolon can decrease simvastatin effect, 6 patients get this two drugs together. This interaction is serious, so it needs to change simvastatin with other lowering cholesterol agents. Methylprednisolon also potentially decrease atorvastatin effect, but atorvastatin can increase methylprednisolon level, so can increase the side effect risk, found in 5 patients. The use of methylprednisolon together with aspirin is common, cause SLE patients need blood thinner to prevent atherosclerosis. Interaction between methylprednisolon and aspirin, is at risk of increasing toxicity so can increase the risk of gastrointestinal bleeding(Day et al., 1988). To the SLE patients who receive this drug combinations (14 persons) proton pump inhibitor are prescribed, such as omeprazole and lanzoprazole, to prevent the occurrence of gastric ulcer. There are also drugs that can increase the effects of corticosteroids, such as atorvastatin and spironolactone, each prescribed with corticosteroids in 4 patients. The use of corticosteroids along with amlodipine and nifedipine, which are present in 9 and 2 SLE patients, respectively, will reduce the antihypertensive effect, so that blood pressure monitoring must be routinely performed.

\section{Conclusion}

The conclusion of this research is methylprednisolon is the most corticosteroid used in SLE outpatients. Corticosteroids are given in combination with other immunsupresive agent, the most is mycophenolat mofetyl. Most corticosteroids $(58,33 \%)$ are given together with Calcium and 
Vitamin D3 to avoid osteoporosis accidents. On this research,44 (22,92\%)potensial interactions were found between corticosteroids and other drugs which given together, the most are between corticosteroids and aspirin, happened in 14 subjects $(7,29 \%)$.

\section{References}

Bachen EA, Chesney MA, Criswell LA,Prevalence of mood and anxiety disorders in women with systemic lupus erythematosus. Arthritis Rheum. 2009 Jun 15; 61(6):822-9.

Bitencourt Dias, C., Pinheiro, C.C., Malafronte, P., Titan, S., Alves de Brito, G., Gera Abrão, J., Dos Santos Silva, V., Toledo Barros, R., Woronik, V., 2011. Prednisone monotherapy induced remission in a group of patients with membranous lupus nephritis. Clin. Nephrol. 76, 57-63.

Chatham, W.W., Kimberly, R.P., 2001. Treatment of lupus with corticosteroids. Lupus 10, 140-147.

Day, R.O., Harris, G., Brown, M., Graham, G.G., Champion, G.D., 1988. Interaction of salicylate and corticosteroids in man. Br. J. Clin. Pharmacol. 26, 334-337.

Hu, W.X., Chen, Y.H., Bao, H., Liu, Z.Z., Wang, S.F., Zhang, H.T., Liu, Z.H., 2015. Glucocorticoid with or without additional immunosuppressant therapy for patients with lupus podocytopathy: a retrospective single-center study. Lupus 24, 1067-1075.
Kasturi, S., Sammaritano, L.R., 2016. Corticosteroids in Lupus. Rheum. Dis. Clin. 42, 47-62. doi:10.1016/j.rdc.2015.08.007

Moroni, G., Ponticelli, C., 2017. Synthetic pharmacotherapy for lupus nephritis. Expert Opin. Pharmacother. 18, 175186.

Ruiz-Irastorza, G., Danza, A., Khamashta, M., 2012. Glucocorticoid use and abuse in SLE. Rheumatol. Oxf. Engl. 51, 11451153.

Setiawati MCN, 2014,Evaluasi Penggunaan Obat, Pengukuran Aktivitas Penyakit dan Pemberian Konseling Pasien Systemic Lupus Erythematosus (SLE), MFI vol 9 No 2, 706-789

Tsang-A-Sjoe, M.W.P., Bultink, I.E.M., 2015. Systemic lupus erythematosus: review of synthetic drugs. Expert Opin. Pharmacother. 16, 2793-2806.

Wung, P.K., Anderson, T., Fontaine, K.R., Hoffman, G.S., Specks, U., Merkel, P.A., Spiera, R., Davis, J.C., St.Clair, E.W., Mccune, W.J., Stone, J.H., 2008. Effects of Glucocorticoids on Weight Change During the Treatment of Wegener's Granulomatosis. Arthritis Rheum. 59, 746-753.

Youssef, J., Novosad, S.A., Winthrop, K.L., 2016. Infection Risk and Safety of Corticosteroid Use. Rheum. Dis. Clin. North Am. 42, 157-176, ix-x. 